\title{
BẤT THƯờng HỒI LỦU TĨNH MẠCH PHỔI TOÀN PHẦn THỂ TRÊN TIM Ở Độ TUỔI 54
}

Bùi Minh Thành*, Phạm Cao Duy*, Đặng Lê Hồng Ngân*, Nguyễn Tất Bình*

\section{TÓM TẮT}

Bất thường hồi lưu tĩnh mạch phổi toàn phần thể trên tim thường hiếm gặp ở người trưởng thành, và là một bệnh lý tim bẩm sinh thường được phẫu thuật trong giai đoạn sơ sinh và hầu hết là ở tình trạng cấp cứu. Chúng tôi báo cáo một trường hợp bệnh nhân được chẩn đoán bệnh ở độ tuổi trưởng thành và được phẫu thuật sửa chữa hoàn toàn vào năm 54 tuổi, khoảng 4 năm sau khi triệu chứng lâm sàng ngày càng nặng dần.

Tù̀ khóa: bất thường hồi lưu tĩnh mạch phổi toàn phần, người trưởng thành.

\section{SUMMARY}

\section{TOTAL SUPRA-CARDIAC ANOMALOUS}

PULMONARY VENOUS RETURN

\section{IN A 54 YEAR OLD MAN}

Bui Minh Thanh, Pham Cao Duy, Dang Le Hong Ngan, Nguyen Tat Binh

Total anomalous pulmonary venous return is a rare congenital heart disease in adult and usually requires surgical correction within the first few months of life. We report results of a 54 year old man with total supra-cardiac anomalous pulmonary venous return who was presented with congestive right heart failure and underwent completed surgical correction.

Key words: total supra-cardiac anomalous pulmonary venous return, adult.

\section{I. ĐẶT VẤN ĐỀ}

Bất thường hồi lưu tĩnh mạch phổi toàn phần (BTHLTMPTP) là một bệnh cảnh hiếm gặp, có tần suất khoảng $0.7-1.5 \%$ trong số các bệnh lý tim bẩm sinh[6]. Hầu hết bệnh nhân với BTHLTMPTP có tử suất là $50 \%$ trong vòng 3 tháng đầu sau sinh và sống trung bình được 2 tháng, hầu hết trẻ sơ sinh chết do suy tim cấp nếu không có can thiệp phẫu thuật[3]. Vì vậy, trường hợp bệnh nhân nam với BTHLTMPTP thể trên tim chưa từng trãi qua phẫu thuật đã sống sót đến độ tuổi 54 là một trường hợp hiếm gặp. Chúng tôi đã phẫu thuật sửa chữa thành công chuyển hồi lưu toàn bộ tĩnh mạch phổi về nhĩ trái khi các triệu chứng của bệnh nhân ngày càng nặng dần sau 4 năm.

\section{GIỚI THIỆU BỆNH ÁN}

Bệnh nhân nam 54 tuổi, làm nông, được phát hiện bệnh lý tim bẩm sinh ở độ tuổi 38 trong một lần tình cờ khám sức khỏe tổng quát. Bệnh nhân được tư vấn phẫu thuật nhưng từ chối do điều kiện kinh tế cá nhân. Đến năm 50 tuổi, các triệu chứng khó thở, phù chân, báng bụng bắt đầu xuất hiện, từ đó điều trị nội khoa cho đến khi được phẫu thuật. Trong khi trước đó 4 năm bệnh nhân vẫn có thể làm những việc nhẹ nhàng và sinh hoạt khá bình thường thì lúc vào viện, bệnh nhân khó thở khi đi lại trên đường bằng (khoảng 200m), hạn chế nhiều các hoạt động gắng sức. Khám lâm sàng ghi nhận: thể trạng gầy với $\mathrm{BMI}=14.4 \mathrm{~kg} / \mathrm{m} 2$, tím nhẹ, tim đều rõ, không phù, không cổ trướng, gan lách không sờ chạm, huyết áp 120/70mmHg, nhịp tim dao động $80-901 / \mathrm{p}$.

Kết quả xét nghiệm cho thấy NT ProBNP là $819.1 \mathrm{pg} / \mathrm{mL}$. Chức năng thận và men gan trong giới hạn bình thường nhưng tăng nhẹ bilirubin toàn phần. Mức huyết sắc tố là $16.7 \mathrm{~g} / \mathrm{dL}$ và dung tích hồng cầu là $47.8 \%$.

Điện tâm đồ ghi nhận lớn thất phải và nhĩ phải, kèm với hình ảnh block nhánh phải.

* Khoa Phẫu thuật Tim, BV Nhân dân Gia Định Ngườ chịu trách nhiệm khoa học: TS. Bùi Minh Thành Ngày nhận bài: 01/05/2018 - Ngày Cho Phép Đăng: 20/05/2018

Phản Biện Khoa học: GS.TS. Bùi Đức Phú PGS.TS. Đặng Ngọc Hùng 
Siêu âm tim cho thấy hồi lưu bất thường tĩnh mạch phổi toàn phần thể trên tim với 4 tĩnh mạch phổi đổ vào ống thu thập, nối vào tĩnh mạch chủ trên trái qua tĩnh mạch tay đầu vào tĩnh mạch chủ trên phải sau đó đổ vào nhĩ phải. Giãn lớn nhĩ phải và thất phải, chức năng thất trái duy trì bình thường. Thêm vào đó là lỗ thông liên nhĩ thứ phát với $\mathrm{d}=15.7 \mathrm{~mm}$ chiều luồng thông phải trái. Hở van 3 lá nặng (4/4). Tăng áp lực động mạch phổi với PAPs $=65 \mathrm{mmHg}$.
Chụp cắt lớp vi tính xác định lại kết quả của siêu âm tim với lỗ thông liên nhĩ lỗ thứ phát lớn với kích thước $18 \mathrm{~mm}$, tất cả tĩnh mạch phổi đổ về ống thu thập rồi đổ vào tĩnh mạch vô danh cuối cùng đổ vào tĩnh mạch chủ trên bên phải rồi vào nhĩ phải. Dãn to thất phải và nhĩ phải với kích thước lần lượt là $57 \mathrm{~mm}$ và $67 \mathrm{~mm}$, dãn to thân và các nhánh động mạch phổi. Không ghi nhận bất thường khác của tim và mạch máu (Hình 1 ).
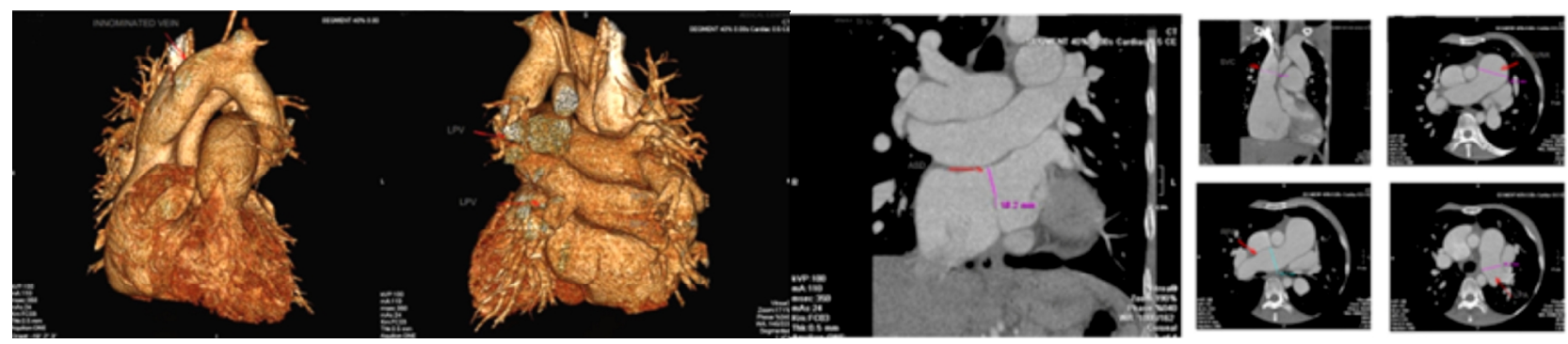

Hình 1: Hình ảnh chup cắt lớp vi tính tim truớc phẫu thuật

Bệnh nhân được phẫu thuật bằng đường mở ngực giữa xương ức $(20 / 09 / 2016)$, với tuần hoàn ngoài cơ thể và hạ thân nhiệt $30^{\circ} \mathrm{C}$. Phẫu tích toàn bộ ống thu thập từ bốn tĩnh mạch phổi, tĩnh mạch vô danh... và chuyển toàn bộ hồi lưu tĩnh mạch phổi vào nhĩ trái, qua miệng nối trực tiếp bên-bên giữa ống thu thập và buồng nhĩ trái phía sau tim. Thông liên nhĩ

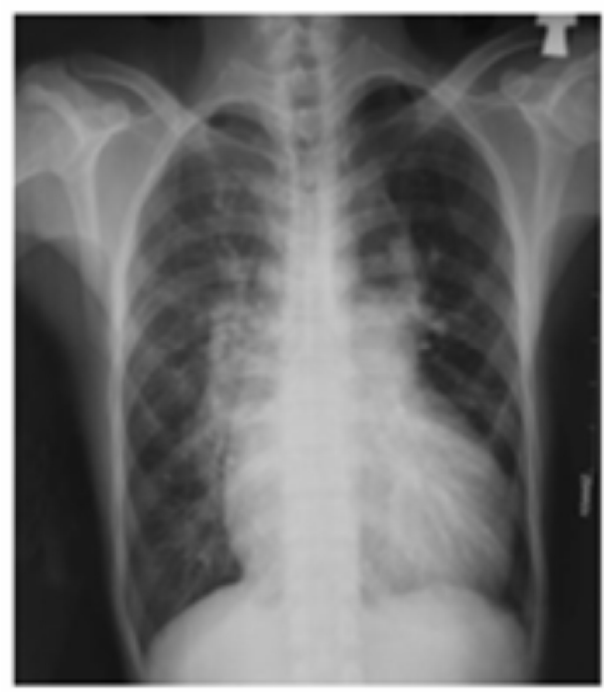

Hình 2: Xquang tim phổi thẳng trước phẫu thuật được đóng bằng màng ngoài tim đã xử lý glutaraldehyde, đồng thời sửa van ba lá với vòng van Taylor size 29. Diễn tiến hậu phẫu ổn định dần. Tái khám sau ba tháng bệnh nhân còn suy tim với NYHA II, mặc dù vẫn chưa hoạt động gắng sức được nhưng các triệu chứng của suy tim thuyên giảm một cách đáng kể.

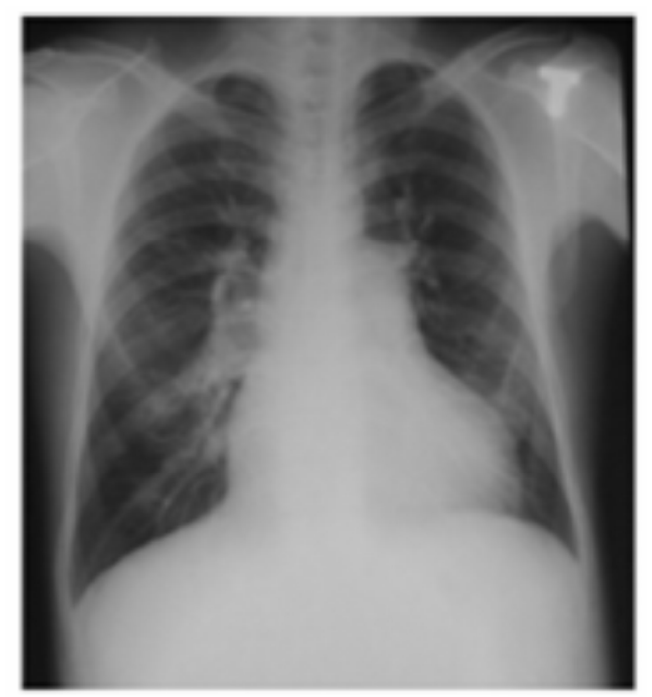

Hình 3: Xquang tim phổi thẳng sau phẫu thuật 3 tháng 
Hình ảnh $\mathrm{X}$ quang cho thấy bóng tim sau mổ thu nhỏ hơn so với trước mổ (Hình 2,3). Siêu âm tim cho thấy giảm kích thước thất phải, nhĩ phải, $\mathrm{EF}=74 \%$.

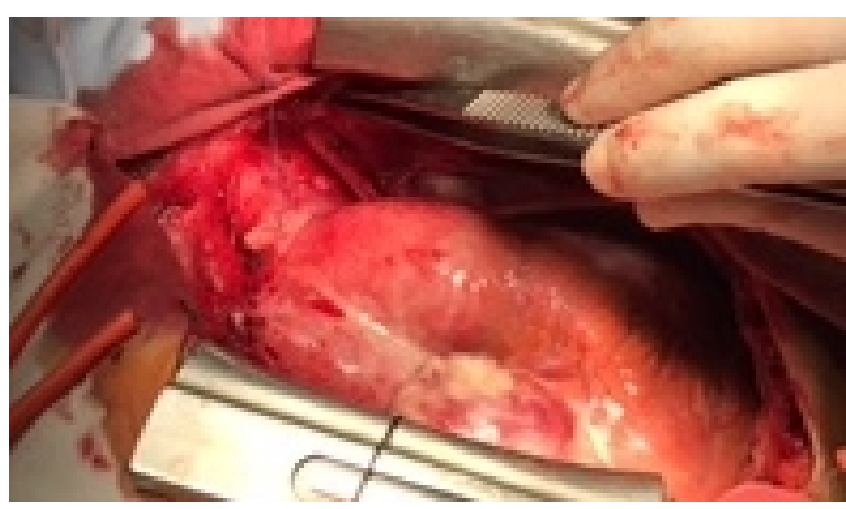

Phẫu tích ống thu thập các tĩnh mạch phổi

Tái khám sau 8 tháng, bệnh nhân có thể sinh hoạt và vận động thể lực bình thường, suy tim được cải thiện nhiều và không có loạn nhịp. Kết quả xét nghiệm NT Pro-BNP ghi nhận lúc tái khám là $78,87 \mathrm{pg} / \mathrm{mL}$. Hình ảnh

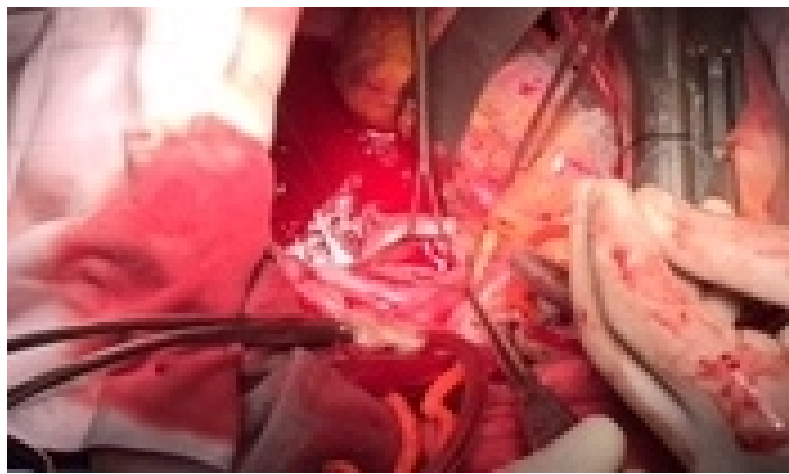

Miệng nối bên-bên: ống thu thập nhĩ trái chụp cắt lớp vi tính kiểm tra (Hình 4) cho thấy bốn tĩnh mạch phổi trở về nhĩ trái, không thấy dấu hiệu hẹp miệng nối hay các tĩnh mạch phổi, kích thước buồng thất phải là $27 \mathrm{~mm}$ và buồng nhĩ phải là $37 \mathrm{~mm}$.
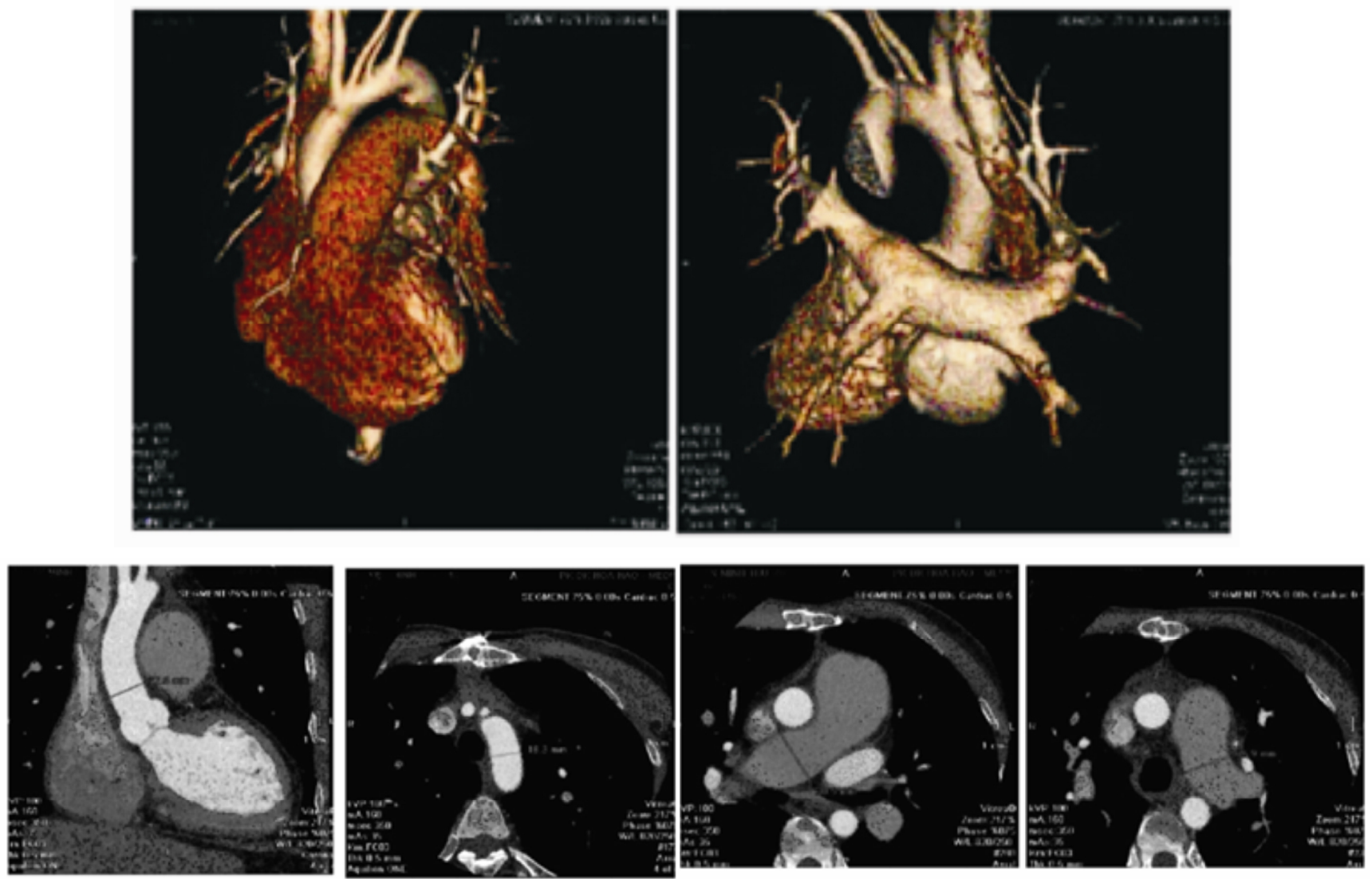

Hình 4: Hình ảnh chụp cắt lớp vi tính tim sau phẫu thuật 


\section{BÀN LUẬN}

Theo Darling, BTHLTMPTP được chia thành 4 thể dựa vào vị trí đổ về của tĩnh mạch phổi trong đó thể trên tim chiếm tỉ lệ cao nhất. Ở trường hợp này, thể trên tim được xác định khi 4 tĩnh mạch phổi đổ vào ống thu thập sau đó vào tĩnh mạch vô danh tiếp đến tĩnh mạch chủ trên bên phải và cuối cùng đổ vào nhĩ phải. Tuy nhiên, ở độ tuổi của trường hợp này thì hiếm gặp vì hầu hết đều tử vong trong thời kỳ sơ sinh do tắc nghẽn hoặc do suy tim cấp nếu không được can thiệp phẫu thuật[3]. Bất thường này là nguyên nhân gây ra tím và dẫn đến tử vong nhanh chóng khi máu không thể lưu thông từ phổi đến tuần hoàn hệ thống. Chính vì thế để có thể sống sót đến tuổi trưởng thành, thường phải tồn tại luồng thông qua vách liên nhĩ: thông liên nhĩ, hoặc lỗ bầu dục hoặc hiếm hơn là thông qua ống động mạch [4]. Do vậy, việc sống sót ở bệnh nhân có BTHLTMPTP phụ thuộc vào có hay không có tắc nghẽn tĩnh mạch phổi và độ lớn của thông liên nhĩ. Trong trường hợp tắc nghẽn, tĩnh mạch phổi thường bị chèn ép bởi các cấu trúc xung quanh dẫn đến tắc nghẽn nặng dòng máu tĩnh mạch phổi, kết quả gây nên gia tăng tăng áp lực động mạch phổi, dẫn đến tăng kháng lực mạch máu phổi, và cuối cùng dẫn đến giãn lớn thất phải và suy tim phải. Sự tắc nghẽn thường xảy ra trong vài ngày sau sinh, bệnh nhân thường tử vong trong vòng 1 tháng đầu đời. Trong khi đó, trong trường hợp không có tắc nghẽn đường đi của dòng máu tĩnh mạch phổi, nhưng với một $10 \hat{\text { ô }}$ thông liên nhĩ hạn chế, ở những bệnh nhân này tử vong khoảng $80 \%$ trong năm đầu sau sinh vì suy tim nặng, chậm lớn và nhiễm trùng phổi tái diễn. Mặc dù không thường gặp nhưng bệnh nhân có BTHLTMPTP nếu hội đủ 2 điều kiện là không tắc nghẽn và có lỗ thông liên nhĩ lớn có thể sống sót đến tuổi trưởng thành. Lịch sử đã ghi nhận vài trường hợp BTHLTMPTP ở người lớn [2][8][9] và có 4 trường hợp được chẩn đoán sau 60 tuổi và 3 trong số đó được phẫu thuật thành công vào năm 61 tuổi [1] 63 tuổi [7] và 66 tuổi [5].
Về trường hợp của chúng tôi, bệnh nhân được chẩn đoán từ trước đó nhưng từ chối phẫu thuật. Mãi đến 12 năm sau, khi có biểu hiện các triệu chứng suy tim phải và sau khi điều trị nội khoa bốn năm, bệnh nhân được phẫu thuật sửa chữa hoàn toàn. Sau ba tháng hậu phẫu, diễn tiến lâm sàng khá tốt. Siêu âm tim kiểm tra kích thước nhĩ phải giảm hẳn, giảm áp lực động mạch phổi và cải thiện rõ chức năng thất phải.

Những trường hợp phẫu thuật sửa chữa BTHLTMPTP ở trẻ em cho thấy kết quả rất tốt về lâu dài, không có loạn nhịp xảy ra muộn hoặc đột tử sau đó. Nguy cơ dự hậu tiềm tàng ở trẻ em là sự hình thành tắc nghẽn mạch máu hay ở miệng nối vì sự tăng sản và lớn lên sinh lý. Trái lại, chúng ta sẽ hiếm gặp điều tương tự ở người lớn. Mặc dù, hầu hết bệnh nhân có BTHLTMPTP đều được chẩn đoán và phẫu thuật ở thời thơ ấu, nhưng trong thực tế vẫn có thể gặp những trường hợp hiếm ở người trưởng thành. Như đã bàn luận ở trên, những điều kiện thuận lợi cho việc sống sót đến tuổi trưởng thành có thể xảy ra, nhưng sau khi kiểm soát suy thất phải bằng điều trị nội khoa thì phẫu thuật là giải pháp điều trị chọn lựa và hiệu quả để có kết quả và tiên lượng tốt hơn.

\section{TÀI LIẸU THAM KHẢO}

1. Melki J., Kovarsky S., Redonnet M., et al. (1992), "[Total anomalous pulmonary venous return in a 61 year-old adult]", Annales de chirurgie, 46 (8), pp. 722-724.

2. Mycinski C., Doll G., Chantepie A., et al. (1989), "[Total abnormal pulmonary venous return surgically treated in an adult]", Arch Mal Coeur Vaiss, 82 (5), pp. 815-817.

3. Vicente W. V., Dias-da-Silva P. S., Vicente Lde M., et al. (2006), "Surgical correction of total anomalous pulmonary venous drainage in an adult", Arq Bras Cardiol, 87 (5), pp. e172-175. 
4. Dillman J. R., Yarram S. G., Hernandez R. J. (2009), "Imaging of pulmonary venous developmental anomalies", $A J R \quad A m J$ Roentgenol, 192 (5), pp. 1272-1285.

5. McMullan M. H., Fyke F. E., 3rd (1992), "Total anomalous pulmonary venous connection: surgical correction in a 66-year-old man", Ann Thorac Surg, 53 (3), pp. 520-521; discussion 521-522.

6. Reller M. D., Strickland M. J., RiehleColarusso T., et al. (2008), "Prevalence of congenital heart defects in metropolitan Atlanta, 1998-2005", J Pediatr, 153 (6), pp. 807-813.

7. Wetzel U., Scholtz W., Bogunovic N., et al. (2010), "Successful correction of a total anomalous venous connection in a 63-year-old male--case report and review of the literature", Congenit Heart Dis, 5 (5), pp. 470-475.

8. Billig Donai M., Peguero Frederico A. (1976), "Total Anomalous Pulmonary Venous Return: Successful Total Correction in a 44-year-old Man with Subtotal Absence of Interatrial Septum, Tricuspid Insufficiency, and Cardiac Dextroversion", Chest, 69 (5), pp. 687-690.

9. Singh Rajindar, Weisinger Barbara, Carpenter Martha, et al. (1971), "Total Anomalous Pulmonary Venous Return, Surgically Corrected in Two Patients beyond 40 Years of Age", Chest, 60 (1), pp. 38-43. 